\title{
Effect of an improved local ingredient-based complementary food fortified or not with iron and selected multiple micronutrients on $\mathrm{Hb}$ concentration
}

\author{
Hermann Z Ouédraogo ${ }^{1, *}$, Tahirou Traoré2 ${ }^{2}$ Augustin N Zèba ${ }^{1}$, \\ Michèle Dramaix-Wilmet ${ }^{3}$, Philippe Hennart ${ }^{4}$ and Philippe Donnen ${ }^{4}$ \\ ${ }^{1}$ Biomedical and Public Health Department, Institute of Research in Health Sciences, 03 BP 5608, \\ Ouagadougou, Burkina Faso: ${ }^{2}$ NutriFaso Project, Ouagadougou, Burkina Faso: ${ }^{3}$ Department of Biostatistics, \\ School of Public Health, Université Libre de Bruxelles, Belgium: ${ }^{4}$ Department of Epidemiology and Preventive \\ Medicine, School of Public Health, Université Libre de Bruxelles, Belgium
}

Submitted 20 July 2009: Accepted 15 March 2010: First published online 8 June 2010

\begin{abstract}
Objective: To assess the effect of an improved local ingredient-based gruel fortified or not with selected multiple micronutrients (MM) on Hb concentration of young children.

Design: In a nutrition centre that we opened in their villages, children received either MM supplement (containing iron, zinc, vitamin A, vitamin $\mathrm{C}$ and iodine) with the improved gruel (MMGG) or the improved gruel only (GG), twice daily, $6 \mathrm{~d} /$ week, for 6 months. We assessed baseline and endpoint $\mathrm{Hb}$ concentration and anthropometric indices.

Setting: Kongoussi, a rural and poor district of Burkina Faso.

Subjects: In a community-based trial, we randomly assigned 131 children aged 6-23 months with $\mathrm{Hb}$ concentrations in the range of 80-109 g/l into two groups. Results: The groups did not differ significantly at baseline. Mean baseline $\mathrm{Hb}$ concentration was 89.2 (sD 6.5) g/l and 90.3 (sD 8.4) g/l in the GG and the MMGG, respectively $(P=0 \cdot 42)$. It increased to $104 \cdot 1($ sD $11 \cdot 4) \mathrm{g} / \mathrm{l}$ in the $\mathrm{GG}(P<0 \cdot 001)$ and $107.6($ sD 14.7$) \mathrm{g} / 1$ in the MMGG $(P<0 \cdot 001)$. The between-group difference of $3.5(95 \% \mathrm{CI}-1 \cdot 0,8 \cdot 1) \mathrm{g} / 1$ in mean (SD) endpoint $\mathrm{Hb}$ concentration was not significant $(P=0 \cdot 13)$. The endpoint anthropometric indices were not different between the groups.

Conclusions: This MM supplement had no additional effect on $\mathrm{Hb}$ concentration. Thorough studies are needed to evaluate the actual efficacy of the gruel before its introduction into household routine.
\end{abstract}

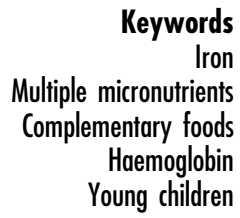

Malnutrition is responsible for $2 \cdot 1$ million deaths in children aged $<5$ years, i.e. $21 \%$ of worldwide deaths in children, with higher relative and absolute effects among African children ${ }^{(1)}$. During weaning, when infants pass from breast milk to a semi-solid and then solid diet, the lack of suitable complementary foods is a major cause of malnutrition ${ }^{(2)}$. Complementary foods must provide 845, 1284 and $2293 \mathrm{~kJ}(202,307$ and $548 \mathrm{kcal}) / \mathrm{d}$ (with at least $4.5,3 \cdot 0$ and $1.0 \mathrm{mg}$ of iron per $418 \mathrm{~kJ}(100 \mathrm{kcal})$ food) to children aged 6-8 months, 9-11 months and 12-23 months, respectively ${ }^{(3)}$. Micronutrient malnutrition, especially iron, zinc, vitamin A and iodine deficiencies, is associated with many health issues, including growth faltering and anaemia.

Anaemia is a widespread public health problem affecting mainly pregnant women and young children ${ }^{(4)}$. Iron deficiency is the main cause of anaemia in many developing countries, but other micronutrient deficiencies besides iron, such as vitamin $\mathrm{B}_{12}$, folate and vitamin $\mathrm{A}$, can also cause anaemia.

Strategies to control micronutrient malnutrition consist of food-based strategies such as dietary diversification and food fortification, as well as nutrition education, public health and food safety measures, and finally supplementation $^{(5)}$. Of these options that aim at increasing intakes, supplementation often provides the fastest improvement in the micronutrient status of individuals or targeted population groups, whereas food-based strategies take longer to implement but are regarded as more sustainable ${ }^{(5)}$. The co-existence of iron deficiency with other micronutrient deficiencies makes combined micronutrient supplementation attractive for the prevention of anaemia. Indeed, addition of multiple micronutrients (MM) to iron supplementation can, even marginally, improve $\mathrm{Hb}$ response 
compared with iron supplementation alone ${ }^{(6)}$; further effects on growth are expected from some of the additional micronutrients ${ }^{(7)}$.

In malaria-endemic areas, the WHO recommends administering iron-containing supplements along with processed complementary foods, since a recent study showed that such supplements administered alone are associated with increased risk of severe illness and death in populations with high prevalence of malaria ${ }^{(8)}$. This makes food-based strategies central to anaemia control, in addition to being more sustainable. Home fortification of complementary foods with micronutrients by using powders, crushable tablets or fat-based products was presented as a potential means to control iron deficiency and anaemia in developing countries ${ }^{(9-11)}$.

In rural Burkina Faso, traditional complementary foods are based on unprocessed cereals. Therefore, they could limit the effect of the supplement depending on their content of iron absorption inhibitors, namely phytates ${ }^{(9)}$. One of the proposed alternatives is to reduce the phytate content in food before the supplement is added ${ }^{(9)}$. Processing techniques such as dehulling, soaking, drying, fermentation and germination are all viable householdlevel techniques for removing phytates ${ }^{(12,13)}$. Some studies have proposed technologies for improving the nutritional quality of the complementary foods used in developing countries ${ }^{(14-16)}$. We undertook the present study in a malaria-endemic area with the aim of assessing the effects of an improved local ingredient-based gruel fortified or not with selected MM on $\mathrm{Hb}$ concentration in young children.

\section{Methods}

\section{Study site}

In rural Burkina Faso, the death rate of children under 5 years of age reached 202 per 1000 living births in $2004^{(17)}$. Stunting affects $41.6 \%$ of children aged $<5$ years, underlining low energy intake ${ }^{(18)}$ and high levels of morbidity and micronutrient deficiencies. The prevalence of anaemia among children aged 6-59 months is $93.6 \%$, thus predicting high prevalence of iron deficiency, though malaria is also highly prevalent ${ }^{(19)}$. The complementary foods mainly consist of cereal-based gruel, which generally has a low energy density of about $167 \mathrm{~kJ}$ (40 kcal)/100 $\mathrm{g}^{(20)}$; children aged 6-23 months consume an average of $14 \mathrm{~g} / \mathrm{kg}$ body weight per meal ${ }^{(21)}$. The study was conducted at Kongoussi, a poor rural district with 256205 inhabitants, $12 \%$ of whom were younger than 2 years.

\section{Study design and subjects}

We performed this community-based randomised trial from January to June 2006. Criteria for enrolment were 6-23 months of age, $\mathrm{Hb}$ concentration in the range of 80-109 g/l, plasma C-reactive protein (CRP) of $<10 \mathrm{mg} / \mathrm{l}$,

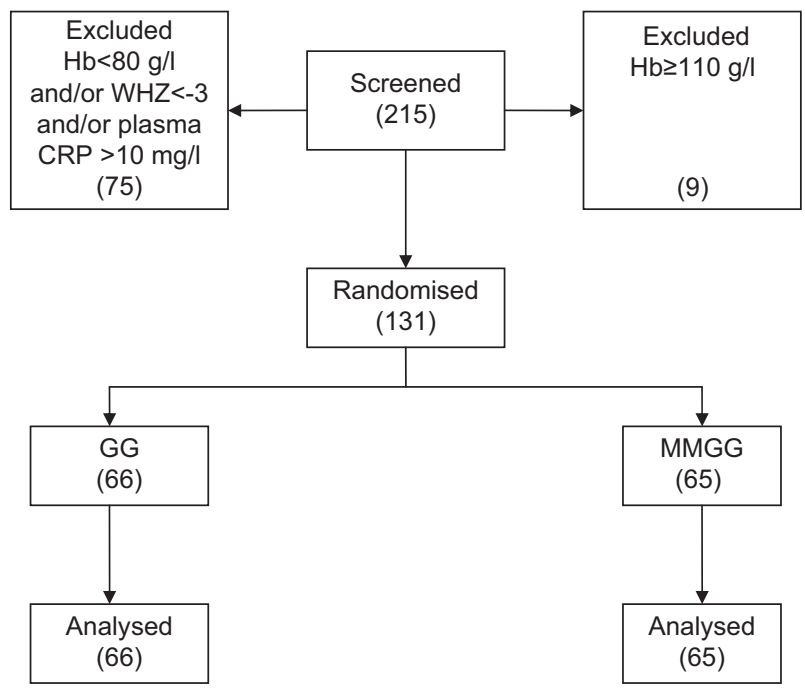

Fig. 1 Trial participant profile (WHZ, weight-for-height Z-score; CRP, plasma C-reactive protein; GG, gruel group includes children who received twice daily the improved gruel $6 \mathrm{~d} /$ week for 6 months; MMGG, gruel with multiple micronutrient supplement group includes children who received twice daily the improved gruel with a once-daily supplement made of $8 \mathrm{mg}$ iron, $5 \mathrm{mg}$ zinc, $300 \mu \mathrm{g}$ vitamin A, $30 \mathrm{mg}$ ascorbic acid and $60 \mu \mathrm{g}$ iodine $6 \mathrm{~d} /$ week for 6 months)

absence of severe wasting (weight-for-height Z-score (WHZ) less than -3), ongoing complementary feeding or caretaker's agreement to introduce complementary foods, and caretaker's consent to child's participation. We drew 215 children from twenty-seven villages (eight children in each village) who had been selected using the 'probability proportionate to size' cluster sampling method used in a previous study ${ }^{(22)}$, and invited them to attend the village health post on a fixed day for screening. Eligible children were randomly assigned in a block design into an improved gruel group (GG, $n$ 66) or an improved gruel and MM group (MMGG, $n$ 65; Fig. 1). In each village, each child could be assigned to GG or MMGG. The assignment to GG or MMGG was made by asking the child's mother to pick one card from an envelope with twenty cards (ten cards corresponded to each group). The next envelope was opened only after all the cards in the previous envelope had been allocated. We calculated the sample size to allow for the detection of a between-group difference of $7 \mathrm{~g} / \mathrm{l}$ in $\mathrm{Hb}$ concentration at $80 \%$ power and 5\% two-side type error, assuming a standard deviation of $13 \mathrm{~g} / 1$. These hypotheses were based on published studies ${ }^{(19,23)}$. We needed to include at least fifty-three children per group to compare endpoint $\mathrm{Hb}$ concentration that was the main evaluation criterion. We raised the sample size to sixty-three per group, accounting for about $15 \%$ losses to follow-up.

\section{Intervention}

All children consumed an improved gruel and received malaria and helminth prevention and treatment; the MM supplement was administered to children in the MMGG. 


\section{Improved gruel consumption}

From Monday through Saturday, twice a day at 06.00 and 16.00 hours, for 6 months, each mother took her child to the nutrition centre we had opened in her village. We chose this option of centralising the gruel preparation and distribution in a nutrition centre to allow tracking of the actual gruel consumption, since this argument was crucial for this efficacy evaluation. In the nutrition centre, each mother received the gruel, free of charge, and fed it to her child under supervision.

The gruel was developed and prepared according to a standardised procedure previously described ${ }^{(24)}$. Briefly, we developed a new flour using Alicom ${ }^{\circledR}$ software (UR106/IRD, Montpellier, France). This processed flour was composed of $51.7 \%$ pearl millet (Pennisetum glaucum), $8 \cdot 8 \%$ beans (Phaseolus vulgaris), $7 \cdot 8 \%$ peanuts (Arachis hypogaea), 9.0\% red sorghum (Sorghum bicolor), $9 \cdot 3 \%$ soumbala, $12 \cdot 7 \%$ sucrose and $0.8 \%$ iodised salt. The pearl millet was winnowed, washed, solar-dried and roasted. The beans were winnowed, sorted, dehulled, solar-dried and roasted. The red sorghum was germinated following a traditional procedure. Soumbala is a fermented condiment that was prepared according to tradition using seeds from the néré tree (Parkia biglobosa). Laboratory tests showed that when this improved gruel was prepared with a consistency of $120 \mathrm{~mm} / 30 \mathrm{~s}$ (Bostwick flow distance), its volumetric mass was $103 \mathrm{~g} / 100 \mathrm{ml}$. The three criteria that we evaluated because of their relationship to growth and anaemia were energy density $(431 \mathrm{~kJ}(103 \mathrm{kcal} / 100 \mathrm{~g})$, zinc content $(1 \cdot 2 \mathrm{mg} / 418 \mathrm{~kJ}(100 \mathrm{kcal}))$ and iron content $(2 \cdot 6 \mathrm{mg} / 418 \mathrm{~kJ}$ $(100 \mathrm{kcal}))$. As far as energy was concerned, lipids, proteins and glucides provided $21 \%, 13 \%$ and $66 \%$, respectively.

We recruited one housewife with at least primaryschool education in four of the twenty-seven villages and trained them in the standardised method of flour production. We also recruited one housewife with at least primary-school education in each of the twenty-seven villages and trained them to prepare the gruel, distribute it and track its consumption. The physical and biochemical characteristics of the gruel were measured during their training period and three times during the intervention. We took a sample of gruel from each village during the 4th, 12th and 22nd weeks to measure the energy density, iron and zinc contents. The average (SD) energy densities for the four samples in chronological order were 431 (SD 23), 431 (sD 22), 451 (sD 48) and 424 (SD 36) kJ/100 g. The average iron contents were $2 \cdot 3$ ( $\mathrm{sD} 0 \cdot 5), 2 \cdot 3(\mathrm{SD} 0 \cdot 5)$, $2 \cdot 6(\mathrm{sD} 0.5)$ and $1 \cdot 8(\mathrm{sD} 0 \cdot 8) \mathrm{mg} / 418 \mathrm{~kJ}(100 \mathrm{kcal})$, and the average zinc contents were 1.6 (SD 0.1), 1.6 (SD 0.1), $1 \cdot 7$ (sD $0 \cdot 1)$ and $1 \cdot 6(\mathrm{sD} 0 \cdot 2) \mathrm{mg} / 418 \mathrm{~kJ}(100 \mathrm{kcal})$.

For each child, the volume of gruel to be administered each day was determined according to his age ${ }^{(3)}$. That is, in each of the two feeding sessions, a child received a desired serving of 418 (100 kcal), 628 (150 kcal) or $1151 \mathrm{~kJ}$ ( $275 \mathrm{kcal}$; i.e. 100,150 or $275 \mathrm{ml}$ ) if he was aged 6-8, 9-11 or $12-23$ months, respectively. Thus, the programme provided $86 \%(100 \% \times 6 / 7 d)$ of the energy required from complementary foods if the gruel was consumed at these desired amounts. The volume was adapted each month as the child aged. For 12-23-month-old children, the recommended quantity of $1151 \mathrm{~kJ}$ ( $275 \mathrm{kcal}$ ) per feeding session was maintained over the course of the intervention. At every session, the child received his gruel in a graduated transparent cup. In all cases, if a child finished his desired serving and asked for more, he was given as much as he needed. In addition to the gruel, we counselled mothers to continue habitual feeding practices.

\section{Malaria and belminths prevention and treatment}

Malaria management consisted of prevention and case detection and treatment. All mothers received a longlasting, deltamethrin-impregnated mosquito net, made of $100 \%$ polyester (PermaNet ${ }^{\circledR} 2 \cdot 0$; Vestergaard Frandsen Disease Control Textiles, Lausanne, Switzerland), and instruction for effective use for children. We asked the local surveyor we recruited in each village to help with installing bed nets, regularly checking their quality during the study and replacing damaged ones. All children were screened for malaria at baseline, and then monthly.

Children with a positive smear for malaria either at baseline or at monthly screening, including afebrile infection, were treated with artemether + lumefantrine (Coartem ${ }^{\circledR}$; Novartis Pharma AG, Basel, Switzerland). No child presented with severe malaria. A unique dose of albendazole was given to children at baseline, as a way to control for soil-transmitted helminth infections ${ }^{(25)}$. Children aged 12-23 months received $200 \mathrm{mg}$ albendazole while children aged 6-11 months did not ${ }^{(26)}$. Children with illness (including fever or a history of fever) during the study were referred to the health post for routine treatment.

\section{Multiple micronutrient supplementation}

Fortitech (Fortitech Europe APS, Gadstrup, Denmark) was responsible for the elaboration of the premix of vitamins and mineral, and the U-Pharma laboratory (Instutut de Recherche en Sciences de la Santé (IRSS), Ouagadougou, Burkina Faso), a collaborating centre of the Université Libre de Bruxelles, Belgium, was responsible for the production and quality control of the supplements. The supplements were produced as capsules containing the daily dose, i.e. $8 \mathrm{mg}$ elemental iron (as ferrous fumarate), $5 \mathrm{mg}$ zinc (as zinc gluconate), $300 \mu \mathrm{g}$ vitamin A (as retinyl acetate), $30 \mathrm{mg}$ ascorbic acid and $60 \mu \mathrm{g}$ iodine (as potassium iodate). While children in the GG received only the improved gruel, supplements were given to children of the MMGG in addition to the improved gruel during the morning session or during the afternoon session if the child was not presented at the first session. Because of the risk of micronutrient degradation, especially ascorbic acid, the supplement was added after the gruel was cooked, and then immediately consumed, as 
recommended $^{(9)}$. Mothers were trained to mix the content of a capsule with a small quantity of gruel, as it was important that the child ate the entire portion mixed.

\section{Data collection and processing}

Data collection involved: (i) an interview of the mothers at baseline by using a questionnaire; (ii) a baseline medical examination of mothers and children; (iii) a baseline and monthly malaria detection and treatment; and (iv) tracking of the quantity of gruel consumed and supplement administration by using a form.

The questionnaire elicited baseline demographic and socio-economic data, as well as child's feeding and caring practices and child's morbidity (diarrhoea, fever or cough in the fortnight preceding the interview). Mother's education referred to her past formal school attendance; mothers who did not attend school were classified as uneducated. Mothers brought a sample of the salt consumed in the household, which was tested for iodisation by using rapid test kits (MBI Kits, Chennai, India). A general practitioner examined mothers for goitre determination according to the definition and classification of the International Council for the Control of Iodine Deficiency Disorders ${ }^{(27)}$, and children for splenomegaly as classified according to Hackett ${ }^{(28)}$. A nutritionist performed anthropometrical measurements on children and mothers in agreement with the WHO recommendations ${ }^{(29)}$. Laboratory technicians obtained children's capillary blood through a finger stick for Hb concentration measurement and blood smear preparation. $\mathrm{Hb}$ concentration was measured by using a HemoCue ${ }^{\circledR}$ machine (Hemocue HB 201+, Angelholm, Sweden) to the nearest $1 \mathrm{~g} / \mathrm{l}$. If it was in the range $80-109 \mathrm{~g} / \mathrm{l}$, an average of $5 \mathrm{ml}$ venous blood was drawn by syringe and transferred into a heparinated tube (Vacutest ${ }^{\circledR}$, Arzergrande, Italy). The blood sample was centrifuged at $2000 \mathrm{rev} / \mathrm{min}$ for $10 \mathrm{~min}$, and the separated plasma was immediately deep-frozen and maintained at a temperature below $-20^{\circ} \mathrm{C}$ in the district hospital until analysis. Analysis was performed at the Laboratoire privé d'analyses médicales du Centre in Ouagadougou, the capital city, to determine plasma albumin and CRP by turbidimetric method (Roche Cobas Integra 400, Rotkreuz, Switzerland). Blood smears to detect malaria infection at baseline (prevalent malaria) and monthly (incident malaria) were stained with Giemsa and read in duplicate for the presence or absence of malaria parasites at the local hospital laboratory. Discordant results $(5 \cdot 7 \%$ of all smears examined during the study) underwent a third reading at the laboratory of the IRSS in Ouagadougou. The woman working at the nutrition centre recorded each child's daily gruel consumption on one form, as well as the number of home meals and breast-feeding in the past $24 \mathrm{~h}$ (as reported by his mother). After field control for consistencies, data were double entered and validated using Epi-info version 6.04d (Centers for Disease Control and Prevention, Atlanta, GA, USA), and then analysed under the Statistical Package for Social Sciences statistical software package version $12 \cdot 0$ for Windows (SPSS Inc., Chicago IL, USA). WHZ, Z-scores for height-for-age (HAZ) and weight-for-age (WAZ) and BMI-for-age (BAZ) were computed using the Anthro 2006 software (WHO, Geneva, Switzerland), considering the new WHO reference population. We considered that a child experienced incident malaria if he had at least one positive smear out of the six monthly malaria checking.

Compliance with the supplement was determined in the MMGG as the percentage of achieved days the supplement was reportedly added to the child's gruel. All indicators of the improved gruel consumption were calculated every month; an average over all 6 months was obtained at the end of the intervention. The total monthly quantity of the gruel ingested was obtained by summing all daily volumes that were actually consumed. Multiplying this value by the energy density, iron content or zinc content yielded the total monthly ingested energy, iron or zinc from the gruel (this does not account for the foods eaten at home or the breast milk intakes). Daily intake was defined as the total monthly intake divided by the total number of days in the given month. The percentage of recommended daily requirements was calculated on the basis of the child's daily requirement, taking into account his current age. We used the internationally recommended daily energy requirements from complementary foods ${ }^{(3)}$. Daily iron and zinc requirements were based on the WHO and FAO recommendations ${ }^{(30)}$.

\section{Etbics consideration}

The study received ethics approval from the Comité d'Ethique pour la Recherche en Santé of Burkina Faso. Informed written consent was obtained from caretakers before children's inclusion in the study. Children with severe wasting detected during the screening were referred to the local hospital for treatment and those with $\mathrm{Hb}$ concentration of $<80 \mathrm{~g} / \mathrm{l}$ or who were still anaemic at the end of intervention underwent a 3-month iron therapy $\left(\right.$ Fercefol $^{\circledR}$; Exphar S.A., Brussels, Belgium) free of charge.

\section{Statistical analysis}

We visually checked the normal distribution of quantitative data by using normality plots. We compared baseline characteristics as well as characteristics in the course of the intervention between the two groups by using Student's $t$ test to compare the means, Mann-Whitney's test to compare the medians, and Pearson's $\chi^{2}$ test to compare the proportions. For the within-group comparison of baseline and endpoint values, we used the paired $t$ test to compare means. The main outcomes considered for analysis were endpoint $\mathrm{Hb}$ concentration and change in $\mathrm{Hb}$ concentration. Analysis was by intent-to-treat. The strategy of analysis of each outcome was set in two steps. First, a difference at the end of the intervention between the two groups was assessed by bivariate analysis using Student's $t$ test. Second, a multiple linear regression analysis was 
applied to adjust for potential confounding factors and to test for the interactions. It included variables that were associated with endpoint $\mathrm{Hb}$ concentration (or change in $\mathrm{Hb}$ concentration) with $P$ value $<0 \cdot 10$, i.e. baseline HAZ, baseline $\mathrm{Hb}$ concentration, prevalent and incident malaria parasitaemia. Using the 'forward' selection method, baseline HAZ, baseline $\mathrm{Hb}$ concentration and incident malaria parasitaemia were identified as predictors of endpoint $\mathrm{Hb}$ concentration (or change in $\mathrm{Hb}$ concentration). In each final model, in addition to baseline $\mathrm{HAZ}$, baseline $\mathrm{Hb}$ concentration and incident malaria parasitaemia, age was also entered by using the 'enter' method to allow testing of its interaction. Residuals and collinearity analysis served to verify the application conditions.

\section{Results}

\section{Baseline characteristics}

The trial participant profile is shown in Fig. 1. Of the 215 children who were screened, the 131 (60.9\%) eligible children were randomised into two groups. No death or loss to follow-up was observed. All children who were randomised were included in the analyses. Groups were comparable with respect to baseline characteristics (Table 1).

\section{Characteristics in the course of the intervention}

Mean compliance with the micronutrient supplement was $85 \cdot 3 \%$ (sD $19 \cdot 2 \%$ ) in the MMGG. The proportion of children who experienced incident malaria parasitaemia was $28.8 \%$ and $30 \cdot 8 \%$ in the GG and MMGG, respectively $(P=0 \cdot 48)$.
Table 2 presents intakes from the improved gruel and home feeding numbers in the course of the intervention. Although the difference was not statistically significant, gruel consumption and daily intakes of energy, iron and zinc from the gruel tended to be higher in the GG than in the MMGG. The median (range) energy intake was 113 (27 kcal; 5-55) kJ/kg body weight per $\mathrm{d}$ in the GG and 96 (23 kcal; 3-53) kJ/kg body weight per $\mathrm{d}$ in the MMGG $(P=0 \cdot 23)$. The number of breast-feeds per day was lower in the GG than in the MMGG $(P=0 \cdot 010)$.

\section{Effect of the intervention on Hb concentration and anthropometric indices}

Table 3 presents endpoint $\mathrm{Hb}$ concentration and anthropometric indices by intervention group. Mean baseline $\mathrm{Hb}$ concentration was $89 \cdot 2(\mathrm{sD} 6 \cdot 5) \mathrm{g} / \mathrm{l}$ and $90 \cdot 3(\mathrm{sD} 8 \cdot 4) \mathrm{g} / \mathrm{l}$ in the GG and MMGG, respectively $(P=0 \cdot 42)$. It increased to $104 \cdot 1$ (SD 11.4) $\mathrm{g} / \mathrm{l}$ in the GG $(P<0 \cdot 001)$ and $107 \cdot 6$ (SD 14.7) $\mathrm{g} / \mathrm{l}$ in the MMGG $(P<0 \cdot 001)$, corresponding to an increment of $14 \cdot 8(\mathrm{sD} 11 \cdot 8) \mathrm{g} / \mathrm{l}$ in the GG and $17 \cdot 3(\mathrm{sD} 15 \cdot 8) \mathrm{g} / \mathrm{l}$ in the MMGG. The between-group difference of $3 \cdot 5$ (95\% CI $-1 \cdot 0$, $8 \cdot 1) \mathrm{g} / \mathrm{l}$ in mean (SD) endpoint $\mathrm{Hb}$ concentration was not significant $(P=0 \cdot 13)$. This difference $(95 \% \mathrm{CI}) \mathrm{did}$ not change after multiple linear regression. The interaction terms of the micronutrient supplementation with baseline age $(P=0 \cdot 51)$, baseline $\mathrm{Hb}$ concentration $(P=0 \cdot 30)$ and incident malaria parasitaemia $(P=0.56)$ were not significant. In addition, the change in $\mathrm{Hb}$ concentration was not different between the groups, even after multiple linear regression, and the tested interactions remained non-significant.

Table 1 Baseline characteristics, by intervention group*

\begin{tabular}{|c|c|c|c|c|c|}
\hline & \multicolumn{2}{|c|}{$\begin{array}{c}\mathrm{GG} \\
(n 66)\end{array}$} & \multicolumn{2}{|c|}{$\begin{array}{c}\text { MMGG } \\
(n 65)\end{array}$} & \multirow[b]{2}{*}{$P+$} \\
\hline & Mean or $\%$ & SD & Mean or $\%$ & SD & \\
\hline Use of non-iodised salt in the household (\%) & $19 \cdot 7$ & & $21 \cdot 5$ & & 0.48 \\
\hline Uneducated mothers (\%) & $80 \cdot 3$ & & $81 \cdot 5$ & & 0.52 \\
\hline Mother's BMI $\left(\mathrm{kg} / \mathrm{m}^{2}\right)$ & $20 \cdot 5$ & $2 \cdot 1$ & $21 \cdot 1$ & $2 \cdot 5$ & $0 \cdot 10$ \\
\hline Mother with visible goitre (\%) & $22 \cdot 7$ & & $20 \cdot 0$ & & $0 \cdot 70$ \\
\hline Mother's $\mathrm{Hb}$ concentration $(\mathrm{g} / \mathrm{l})$ & $110 \cdot 1$ & $14 \cdot 1$ & $112 \cdot 7$ & $12 \cdot 1$ & 0.27 \\
\hline Age (months) & $13 \cdot 9$ & $4 \cdot 2$ & $13 \cdot 9$ & $4 \cdot 6$ & 0.95 \\
\hline Sex, male (\%) & $57 \cdot 6$ & & $53 \cdot 8$ & & 0.40 \\
\hline Birth weight $(\mathrm{g})$ & 2826 & 317 & 2802 & 413 & $0 \cdot 70$ \\
\hline No longer breast-fed (\%) & 3.0 & & 1.5 & & 0.51 \\
\hline Morbidity in the last fortnight (\%) & $30 \cdot 3$ & & $29 \cdot 2$ & & 0.52 \\
\hline Prevalent malaria parasitemia (\%) & $37 \cdot 9$ & & $47 \cdot 7$ & & $0 \cdot 17$ \\
\hline Weight $(\mathrm{kg})$ & $8 \cdot 23$ & $1 \cdot 37$ & $8 \cdot 32$ & $1 \cdot 38$ & 0.73 \\
\hline Height $(\mathrm{cm})$ & $73 \cdot 6$ & $5 \cdot 2$ & $73 \cdot 2$ & $5 \cdot 1$ & 0.67 \\
\hline Weight-for-height $Z$-score & $-1 \cdot 18$ & 1.03 & -0.92 & 1.07 & 0.17 \\
\hline Weight-for-age Z-score & -1.51 & $1 \cdot 02$ & $-1 \cdot 35$ & $1 \cdot 14$ & 0.42 \\
\hline Height-for-age Z-score & $-1 \cdot 24$ & 0.92 & $-1 \cdot 28$ & $1 \cdot 29$ & 0.82 \\
\hline BMI-for-age Z-score & -1.05 & 1.07 & -0.72 & $1 \cdot 16$ & 0.09 \\
\hline Plasma C-reactive protein $(\mathrm{mg} / \mathrm{l})$ & $3 \cdot 0$ & $2 \cdot 7$ & $3 \cdot 2$ & $2 \cdot 8$ & 0.63 \\
\hline Plasma albumin $(\mathrm{g} / \mathrm{l})$ & $35 \cdot 6$ & $4 \cdot 7$ & $36 \cdot 0$ & $5 \cdot 2$ & 0.69 \\
\hline Hb concentration $(\mathrm{g} / \mathrm{l})$ & $89 \cdot 2$ & $6 \cdot 5$ & $90 \cdot 3$ & $8 \cdot 4$ & 0.42 \\
\hline
\end{tabular}

*GG, gruel group includes children who received twice-daily the improved gruel $6 \mathrm{~d} /$ week for 6 months; MMGG, gruel with multiple micronutrient supplement group includes children who received twice-daily the improved gruel with once-daily a supplement made of $8 \mathrm{mg}$ iron, $5 \mathrm{mg}$ zinc, $300 \mu \mathrm{g}$ vitamin $\mathrm{A}$, $30 \mathrm{mg}$ ascorbic acid and $60 \mu \mathrm{g}$ iodine $6 \mathrm{~d} /$ week for 6 months.

tBetween-group comparison by using Student's $t$ test for mean and Pearson's $\chi^{2}$ test for proportion (\%). 
Table 2 Intakes from the improved gruel, and home-feeding practices, by intervention group*

\begin{tabular}{|c|c|c|c|c|c|}
\hline & \multicolumn{2}{|c|}{$\begin{array}{l}\mathrm{GG} \\
(n 66)\end{array}$} & \multicolumn{2}{|c|}{$\begin{array}{c}\text { MMGG } \\
(n 65)\end{array}$} & \multirow[b]{2}{*}{$P+$} \\
\hline & Mean & SD & Mean & SD & \\
\hline \multicolumn{6}{|l|}{ Gruel consumption at each session } \\
\hline $\mathrm{g} / \mathrm{meal}$ & 252 & 46 & 245 & 54 & $0 \cdot 40$ \\
\hline $\mathrm{g} / \mathrm{kg}$ body weight per meal & 29 & 4 & 28 & 6 & 0.28 \\
\hline \multirow[t]{2}{*}{ Percentage of the desired serving } & 108 & 18 & 105 & 10 & $0 \cdot 29$ \\
\hline & Median & Range & Median & Range & \\
\hline \multicolumn{6}{|l|}{ Energy intake from the gruel } \\
\hline $\mathrm{kcal} / \mathrm{d} \ddagger$ & 226 & $43-371$ & 192 & $25-373$ & 0.37 \\
\hline $\mathrm{kcal} / \mathrm{kg}$ body weightł & 27 & $5-55$ & 23 & $3-53$ & 0.23 \\
\hline Percentage of requirement from CF & 47 & $12-68$ & 40 & $8-68$ & 0.29 \\
\hline \multicolumn{6}{|l|}{ Iron intake from the gruel } \\
\hline $\mathrm{mg} / \mathrm{d}$ & $5 \cdot 1$ & $1 \cdot 1-9 \cdot 3$ & $4 \cdot 8$ & $0 \cdot 6-9 \cdot 3$ & 0.35 \\
\hline Percentage of recommended intake§ & 81 & $12-160$ & 81 & $7-161$ & 0.52 \\
\hline Percentage of recommended intakell & 39 & $6-80$ & 34 & $3-80$ & 0.56 \\
\hline \multicolumn{6}{|l|}{ Zinc intake from the gruel } \\
\hline $\mathrm{mg} / \mathrm{d}$ & $2 \cdot 2$ & $0 \cdot 5-4 \cdot 1$ & $2 \cdot 1$ & $0 \cdot 3-4 \cdot 1$ & 0.35 \\
\hline Percentage of recommended intake & 54 & $12-100$ & 52 & $7-100$ & 0.36 \\
\hline Percentage of recommended intake ${ }^{\star \star}$ & 27 & $6-49$ & 25 & $3-49$ & 0.36 \\
\hline Daily number of breast-feeding & $5 \cdot 0$ & $3 \cdot 8-17 \cdot 0$ & $6 \cdot 7$ & $2 \cdot 0-15 \cdot 3$ & 0.010 \\
\hline Daily number of home meals & $2 \cdot 0$ & $1 \cdot 0-4 \cdot 9$ & $2 \cdot 0$ & $1 \cdot 0-4 \cdot 7$ & 0.86 \\
\hline
\end{tabular}

CF, complementary foods.

${ }^{*} \mathrm{GG}$, gruel group includes children who received twice-daily the improved gruel $6 \mathrm{~d} /$ week for 6 months; MMGG, gruel with multiple micronutrient supplement group includes children who received twice-daily the improved gruel with once-daily a supplement made of $8 \mathrm{mg}$ iron, $5 \mathrm{mg}$ zinc, $300 \mu \mathrm{g}$ vitamin $\mathrm{A}, 30 \mathrm{mg}$ ascorbic acid and $60 \mu \mathrm{g}$ iodine $6 \mathrm{~d} /$ week for 6 months.

tBetween-group comparison by using Student's $t$ test for mean, Mann-Whitney's test for median, and Pearson's $\chi^{2}$ test for proportion (\%).

$\ddagger 1 \mathrm{kcal}=4 \cdot 184 \mathrm{~kJ}$.

§Assuming $10 \%$ bioavailability.

\|Assuming $5 \%$ bioavailability.

Assuming moderate bioavailability.

${ }^{\star *}$ Assuming low bioavailability.

Table 3 Mean (SD) of baseline and endpoint $\mathrm{Hb}$ concentrations and anthropometric indices, by intervention group*

\begin{tabular}{|c|c|c|c|c|c|c|c|c|c|c|c|c|c|c|c|}
\hline & \multicolumn{5}{|c|}{ Baseline } & \multicolumn{5}{|c|}{ Endpoint } & \multicolumn{5}{|c|}{ Change } \\
\hline & \multicolumn{2}{|c|}{$\begin{array}{c}\mathrm{GG} \\
(n 66)\end{array}$} & \multicolumn{2}{|c|}{$\begin{array}{c}\text { MMGG } \\
(n 65)\end{array}$} & \multirow[b]{2}{*}{$P+$} & \multicolumn{2}{|c|}{$\begin{array}{c}\mathrm{GG} \\
(n 66)\end{array}$} & \multicolumn{2}{|c|}{$\begin{array}{c}\text { MMGG } \\
(n 65)\end{array}$} & \multirow[b]{2}{*}{$P+$} & \multicolumn{2}{|c|}{$\begin{array}{c}\mathrm{GG} \\
(n 66)\end{array}$} & \multicolumn{2}{|c|}{$\begin{array}{c}\text { MMGG } \\
(n 65)\end{array}$} & \multirow[b]{2}{*}{$P+$} \\
\hline & Mean & SD & Mean & SD & & Mean & SD & Mean & SD & & Mean & SD & Mean & SD & \\
\hline $\mathrm{Hb}$ concentration $(\mathrm{g} / \mathrm{l})$ & $89 \cdot 2$ & $6 \cdot 5$ & $90 \cdot 3$ & $8 \cdot 4$ & 0.42 & $104 \cdot 1$ & $11 \cdot 4 \ddagger$ & $107 \cdot 6$ & $14 \cdot 7 \ddagger$ & $0 \cdot 13$ & $14 \cdot 8$ & $11 \cdot 8$ & $17 \cdot 3$ & $15 \cdot 8$ & $0 \cdot 31$ \\
\hline Weight (kg) & $8 \cdot 23$ & $1 \cdot 37$ & $8 \cdot 32$ & $1 \cdot 38$ & 0.73 & $9 \cdot 47$ & $1 \cdot 46 \ddagger$ & $9 \cdot 57$ & $1 \cdot 27 \ddagger$ & 0.67 & $1 \cdot 23$ & $0 \cdot 61$ & $1 \cdot 25$ & 0.66 & 0.86 \\
\hline Height $(\mathrm{cm})$ & $73 \cdot 6$ & $5 \cdot 2$ & $73 \cdot 2$ & $5 \cdot 1$ & 0.67 & $79 \cdot 1$ & $4 \cdot 8 \ddagger$ & $79 \cdot 1$ & $4 \cdot 6 \ddagger$ & 0.96 & $5 \cdot 5$ & $1 \cdot 8$ & $5 \cdot 9$ & $2 \cdot 2$ & 0.23 \\
\hline WHZ & $-1 \cdot 18$ & 1.03 & -0.92 & $1 \cdot 07$ & 0.17 & -0.97 & $1 \cdot 11 \S$ & -0.79 & 0.94 & 0.32 & $0 \cdot 21$ & $0 \cdot 80$ & $0 \cdot 13$ & 0.77 & 0.59 \\
\hline WAZ & $-1 \cdot 51$ & $1 \cdot 02$ & $-1 \cdot 35$ & $1 \cdot 14$ & 0.42 & $-1 \cdot 50$ & $1 \cdot 03$ & $-1 \cdot 34$ & 0.99 & 0.37 & 0.01 & 0.60 & 0.02 & 0.65 & 0.95 \\
\hline HAZ & $-1 \cdot 24$ & 0.92 & $-1 \cdot 28$ & $1 \cdot 29$ & $0 \cdot 82$ & $-1 \cdot 57$ & $0 \cdot 70 \ddagger$ & $-1 \cdot 43$ & $1 \cdot 00 \S$ & 0.40 & -0.33 & $0 \cdot 70$ & $-0 \cdot 19$ & 0.75 & 0.28 \\
\hline BAZ & $-1 \cdot 05$ & $1 \cdot 07$ & -0.72 & $1 \cdot 16$ & 0.09 & $-0 \cdot 78$ & $1 \cdot 22 \S$ & -0.56 & 0.94 & 0.25 & 0.27 & 0.92 & $0 \cdot 15$ & 0.90 & 0.47 \\
\hline
\end{tabular}

WHZ, weight-for-height Z-score; WAZ, weight-for-age Z-score; HAZ, height-for-age Z-score; BAZ, BMI-for-age Z-score.

${ }^{*} \mathrm{GG}$, gruel group includes children who received twice-daily the improved gruel $6 \mathrm{~d} /$ week for 6 months; MMGG, gruel with multiple micronutrient supplement group includes children who received twice-daily the improved gruel with once-daily a supplement made of $8 \mathrm{mg}$ iron, $5 \mathrm{mg}$ zinc, $300 \mu \mathrm{g}$ vitamin A, $30 \mathrm{mg}$ ascorbic acid and $60 \mu \mathrm{g}$ iodine $6 \mathrm{~d} /$ week for 6 months.

tBetween-group comparison by using Student's $t$ test.

$\ddagger P<0.001$ for the paired $t$ test of the within-group comparison.

$\S P<0.05$ for the paired $t$ test of the within-group comparison.

There were no significant differences with respect to endpoint anthropometric indices, i.e. WHZ $(P=0.59)$, WAZ $(P=0 \cdot 95)$, HAZ $(P=0 \cdot 28)$ and BAZ $(P=0 \cdot 47)$.

\section{Discussion}

This MM supplement had no additional effect on $\mathrm{Hb}$ concentration. Yet, the selected MM supplement used in our study was similar to that used in the study by Thu et $a l^{(31)}$, who reported a mean increase in $\mathrm{Hb}$ concentration of $15.5(\mathrm{SD} 13.4) \mathrm{g} / \mathrm{l}$ in the daily MM supplementation group, but a decrease of -0.5 (SD 8.8) $\mathrm{g} / \mathrm{l}$ in the placebo group, i.e. a between-group difference of $16 \mathrm{~g} / \mathrm{l}^{(31)}$. The lack of between-group difference in $\mathrm{Hb}$ concentration in our study could be explained by two reasons.

First, the bioavailability of minerals such as iron and zinc could have been altered in the case of high phytate 
content of this cereal-based gruel. We did not assess the iron and zinc bioavailability from the gruel. We merely assumed that it improved as ingredients were processed using household-level technologies ${ }^{(12,13)}$, and the addition of vitamin $\mathrm{C}$ in the supplement was intended to improve iron bioavailability.

Second, more plausible, is the concurrent consumption of the improved gruel in the GG, instead of placebo. The improvement of the gruel mainly consisted of: (i) a combination of legumes such as peanuts and beans with cereals, thus diversifying the micronutrient sources; (ii) ingredient processing by roasting, dehulling and germinating, thus decreasing the content of anti-nutritional factors such as phytate; and (iii) the incorporation of soumbala that has an iron content of $69.6 \mathrm{mg} / 100 \mathrm{~g}^{(32)}$. Such improved gruel could itself substantially improve $\mathrm{Hb}$ concentration and anthropometric indices. Indeed, the increment of $14.8 \mathrm{~g} / \mathrm{l}$ in $\mathrm{Hb}$ concentration observed in the group that received the improved gruel only is comparable to that of children receiving an iron supplement in a previous trial we conducted in the same population ${ }^{(33)}$. Other studies of improved complementary foods by ingredient processing and/or micronutrient incorporation reported improved $\mathrm{Hb}$ concentration and reduced anaemia prevalence ${ }^{(34-36)}$.

These results suggest that an improved gruel produced with locally available ingredients may be efficacious for improving $\mathrm{Hb}$ concentration and stabilising or improving some anthropometric indices. This is consistent with a study in Ghana in which the incorporation of a premix of vitamins and minerals into infant flour named Weanimix did not have an additional effect on $\mathrm{Hb}$ concentration ${ }^{(37)}$. The authors of the study in Ghana argued, among others, that the tested food, along with frequent breast-feeding, was yet nutritionally adequate. The iron intakes from the improved gruel in the present study were higher than those observed among Ghanaian infants fed Weanimix (mean daily intakes from the project food of $1 \cdot 7,2 \cdot 4,2 \cdot 1$ and $2 \cdot 8 \mathrm{mg} / \mathrm{d}$ when infants were aged $7,8,10$ and 12 months, respectively).

The present study focused on the main nutrients associated with the outcomes we assessed, i.e. energy, iron and zinc. However, as limits, it lacked data about the bioavailability of iron and zinc from the gruel, as well as about children's breast milk intakes during the intervention. A key idea supporting gruel serving is average breast milk intake, which supposes that breast-feeding patterns are maintained throughout the intervention, whereas feeding young children with energy-rich food can lead to displacement of breast milk ${ }^{(3,38)}$. Another concern that can be limiting was that although the research assistant who performed $\mathrm{Hb}$ concentration analysis and anthropometrical measurements was blinded to groups, the principal investigator was not.

To conclude, thorough studies are needed to determine the ingredient processing standard that would lead to the best iron and zinc contents and bioavailability, and to evaluate the actual efficacy of the gruel before its introduction into household routine. This may be a step towards the implementation of the food multimix approach that intends to make better use of traditional food sources to meet community nutritional needs, especially in Sub-Saharan Africa ${ }^{(39)}$.

\section{Acknowledgements}

The present study was supported by a grant from the Nestlé Foundation, Switzerland; Fortitech Europe ApS, Gadstrup, Denmark, made the vitamin mix free of charge. None of the authors had any financial or other conflicts of interest regarding this manuscript. H.Z.O. conducted the study design, fieldwork, data analysis and paper drafting. T.T. conducted the flour formulation, trained the housewives and performed the laboratory analyses. A.N.Z. was involved in the fieldwork and contributed to the paper correction. M.D.W. contributed to the study design, data analysis and interpretation and paper correction. P.H. contributed to data interpretation and paper correction. P.D. contributed to the study design, data analysis and interpretation, and paper correction.

\section{References}

1. Black RE, Allen LH, Bhutta ZA et al. (2008) Maternal and child undernutrition: global and regional exposures and health consequences. Lancet 371, 243-260.

2. World Health Organization (1998) Complementary Feeding of Young Children in Developing Countries: A Review of Current Scientific Knowledge. Geneva: WHO.

3. Dewey KG \& Brown KH (2003) Update on technical issues concerning complementary feeding of young children in developing countries and implications for intervention programs. Food Nutr Bull 24, 5-28.

4. McLean E, Cogswell M, Egli I et al. (2009) Worldwide prevalence of anaemia, WHO Vitamin and Mineral Nutrition Information System, 1993-2005. Public Health Nutr 12, 444-454.

5. World Health Organization (2006) Guidelines of Food Fortification with Micronutrients. Geneva: WHO.

6. Gera T, Sachdev HPS \& Nestel P (2009) Effect of combining multiple micronutrients with iron supplementation on $\mathrm{Hb}$ response in children: systematic review of randomized controlled trials. Public Health Nutr 12, 756-773.

7. Ramakrishnan U, Nguyen P \& Martorell R (2009) Effects of micronutrients on growth of children under 5 y of age: meta-analyses of single and multiple nutrient interventions. Am J Clin Nutr 89, 191-203.

8. World Health Organization (2007) Conclusions and recommendations of the WHO consultation on prevention and control of iron deficiency in infants and young children in malaria-endemic areas. Food Nutr Bull 28, S621-S627.

9. Nestel P, Briend A, De Benoist B et al. (2003) Complementary food supplements to achieve micronutrient adequacy for infants and young children. $J$ Paediatr Gastroenterol Nutr 36, 316-328.

10. Dewey KG \& Adu-Afarwuah S (2008) Systematic review of the efficacy and effectiveness of complementary feeding interventions in developing countries. Matern Child Nutr 4, 24-85. 
11. Ip H, Hyder SMZ, Haseen F et al. (2009) Improved adherence and anaemia cure rates with flexible administration of micronutrient Sprinkles: a new public health approach to anaemia control. Eur J Clin Nutr 63, 165-172.

12. Mensah P \& Tomkins A (2003) Household-level technologies to improve the availability and preparation of adequate and safe complementary foods. Food Nutr Bull 24, 104-124.

13. Gibson RS, Perlas L \& Hotz C (2006) Improving the bioavailability of nutrients in plant foods at the household level. Proc Nutr Soc 65, 160-168.

14. Vieu MC, Traoré T \& Trèche S (2001) Effects of energy density and sweetness of gruels on Burkinabe infant energy intakes in free-living conditions. Int J Food Sci Nutr 52, 213-218.

15. Traore T, Vieu MC, Traoré SA et al. (2005) Effects of the duration of the habituation period on energy intakes from low and high energy density gruels by Burkinabè infants living in free conditions. Appetite 45, 279-286.

16. Moursi M, Mbemba F \& Trèche S (2003) Does the consumption of amylase-containing gruels impact on the energy intake and growth of Congolese infants? Public Health Nutr 6, 249-257.

17. Macro International (2004) Burkina Faso: Enquête Démographique et de Santé 2003-2004 (EDS-BF III). Washington, DC: ORC Macro International.

18. Briend A (2005) Should we add oil to complementary foods for breastfed children in developing countries? J Pediatr Gastroenterol Nutr 41, 12-13.

19. Ouédraogo HZ, Zèba AN, Dramaix-Wilmet M et al. (2008) Severe anaemia due to afebrile Plasmodium falciparum infection in children aged 6-23 months from the rural district of Kongoussi, Burkina Faso. J Trop Pediatr 54, 395-400.

20. Trèche S (2002) Complementary foods in developing countries: importance, required characteristics, constraints and potential strategies for improvement. In Proceedings of the International Colloqum Promoting Growth and Development of Under Fives, pp. 132-148 [P Kolsteren and T Hoerée, editors]. Antwerpen: ITG Press.

21. Noukpoape A (1997) Etude des pratiques alimentaires et de la valeur nutritionnelle des aliments de complément du jeune enfant en milieu rural au Burkina Faso. Montpellier: Université de Montpellier II.

22. Ouédraogo HZ, Nikièma L, Somé I et al. (2008) Homebased practices of complementary foods improvement are associated with better height-for-age Z-score in 12-23 months-old children from a rural district of Burkina Faso. Afr J Food Agric Nutr Dev 8, 204-218.

23. Smuts CM, Lombard CJ, Benade AJ et al. (2005) Efficacy of a foodlet-based multiple micronutrient supplement for preventing growth faltering, anaemia, and micronutrient deficiency of infants: the four country IRIS trial pooled data analysis. J Nutr 135, 631-638.

24. Ouédraogo HZ, Traore T, Zeba AN et al. (2009) Development of a local-ingredient-based improved flour and technology transfer to rural housewives in Burkina Faso. Food Nutr Bull 30, 153-160.
25. Hall A, Hewitt G, Tuffrey V et al. (2008) A review and metaanalysis of the impact of intestinal worms on child growth and nutrition. Matern Child Nutr 4, 118-236.

26. World Health Organization (2002) Report of the WHO Informal Consultation on the Use of Praziquentel in Pregnancy/Lactation and Albendazole/Mebendazole in Children Under 24 Months. Geneva: WHO.

27. International Council for the Control of Iodine Deficiency Disorders (1990) A Practical Guide to the Correction of Iodine Deficiency Disorders [JT Dunn and F Van Der Haar, editors]. Amsterdam: ICCIDD.

28. Gentilini M (1993) Médecine Tropicale, 5th ed. Paris: Flammarion Médecine Sciences.

29. World Health Organization (1995) Physical Status: The Use and Interpretation of Anthropometry. Geneva: WHO.

30. World Health Organization \& Food and Agriculture Organization of the United Nations (2004) Vitamin and Mineral Requirements in Human Nutrition. Geneva: WHO.

31. Thu BD, Schultink W, Dillon D et al. (1999) Effect of daily and weekly micronutrient supplementation on micronutrient deficiencies and growth in young Vietnamese children. Am J Clin Nutr 69, 80-86.

32. Barikmo I, Ouattara F \& Oshaug A (2004) Food Composition Table for Mali. Lillestrøm: Akershus University College.

33. Ouédraogo HZ, Dramaix-Wilmet M, Zèba AN et al. (2008) Effect of iron or multiple micronutrient supplements on the prevalence of anaemia among anaemic young children of a malaria-endemic area: a randomized double-blind trial. Trop Med Int Health 13, 1-10.

34. Faber M, Kvalsvig JD, Lombard CJ et al. (2005) Effect of a fortified maize-meal porridge on anaemia, micronutrient status, and motor development of infants. Am J Clin Nutr 82, 1032-1039.

35. Owino VO, Kasonka LM, Sinkala MM et al. (2007) Fortified complementary foods with or without alpha-amylase treatment increase $\mathrm{Hb}$ but do not reduce breastmilk intake of 9-mo-old Zambian infants. Am J Clin Nutr 86, 1094-1103.

36. Lutter CK, Rodriguez A, Fuenmayor G et al. (2008) Growth and micronutrient status in children receiving a fortified complementary food. J Nutr 138, 379-388.

37. Lartey A, Manu A, Brown KH et al. (1999) A randomised, community-based trial of the effects of improved, centrally processed complementary foods on growth and micronutrient status of Ghanaian infants from 6 to 12 months. Am J Clin Nutr 70, 391-404.

38. Islam MM, Peerson JM, Ahmed T et al. (2006) Effect of varied energy density of complementary foods on breastmilk intakes and total energy consumption by healthy, breastfed Bangladeshi children. Am J Clin Nutr 83, 851-858.

39. Zotor FB \& Amma P (2008) The food multimix concept: new innovative approach to meeting nutritional challenges in Sub-Saharan Africa. Proc Nutr Soc 67, 98-104. 